\title{
STATUS UMETNOSTI U PRVOJ POLOVINI XVIII STOLEĆA
}

\section{Nikola Grdinić}

UDK: 930.85(497.5:497.11)“17“

Sažetak: U ovom radu se istražuje kako funkcionira umjetnost u prvoj polovici 18. stoljeća. Pritom su analizirana četiri primjera slikarskih i književnih djela iz srpske i hrvatske kulture od 1700. do 1770. godine. Pomoću tih primjera moguće je doći do određenih zaključaka. Uočljive su tri vrste promjena: (a) vlastito se zamjenjuje novim i stranim; (b) tradicionalno se kombinira s novim i stranim; (c) Novo se adaptira na tradicionalno. Prikazani su kako primjeri tipa (a) i (b) tako i (c). Umjetnost obilježavaju hibridne vrste i složenost izvanestetskih funkcija. Sintetički pojmovi koji su upotrijebljeni za opis analiziranih primjera - barok, klasicizam, produženo srednjovjekovlje, modernizacija - dobivaju dodatna značenja. Oni su suviše uopćeni i nedovoljno prikladni za analizu ove materije. S predloženim pristupom, ishodišne su točke u analizi stilskih pojava i umjetničkih vrsta kulturološki orijentirano istraživanje tendencija u kulturi te raščlanjivanja na višu i nižu kulturu.

Ključne riječi: srpska umjetnost, hrvatska umjetnost, 18. stoljeće, hibridiziranje, estetika.

U] prvoj polovini XVIII stoleća umetnost ne postoji kao zasebno područje sui generis. To će postati tek u doba pune prosvećenosti. Uostalom, i estetika se kao posebna disiplina konstituiše tek krajem XVIII veka. Promena je nastala na podlozi tri čuvena zahteva za emancipacijom mišljenja: 1) autonomnost u odnosu na spoljašnje uslove ; 2) moralnost, tj. opredeljenje za moralno ponašanje na osnovu sopstvenog uverenja da tako treba, a ne zbog spoljašnjih pritisaka i 3) umetnost koja se emancipuje od toga da služi nečemu što je izvan nje same. Sve do tada smatralo se da umetnost treba biti povezana sa nečim drugim, pa ono što iz današnje perspektive nazivamo umetnošću, jeste subsistem u funkciji ideologije ili politike, može se reći i opštije, društvenog života i kulture. U tome smislu umetnost se $\mathrm{u}$ ovome vremenu pre može posmatrati u vezi sa nečim izvan nje nego sama za sebe. Iz te perspektive, pomoću nje, mogu se razumeti i osvetliti procesi u društvu; promene u formi mišljenja i oblicima izražavanja jednako su značajne kao što su to i tehnološke inovacije, ili promene u društvenim odnosima.

No, iako je ono što danas zovemo umetničkim delima, ili graničnim pojavama, kao što su to grbovnici, ili religijske, prigodne, pozdravne ili zabavne pesme, ponekad i spontani izlivi emocija, one ipak i kada nekoga veličaju ili, ne tako retko, kritikuju ili čak napadaju, to čine rečima koje su složene u nekakav ritmički poredak, sa prenesenim značenjima, kompoziciono uobličene na nekakav poseban način. Ovakva njihova svojstva mogla bi se opisati kao sekundarna. 
Kroz vreme funkcije se menjaju, pa sekundarne postaju primarne, ali ne samo da se menjaju funkcije koje opisujemo kao estetske, već i one funkcije koje pripadaju vanestetskoj sferi. Tačno bi bilo reći da svaka pojava koju promatramo u tome vremenu, svaka pesma, slika ili knjiga ima više funkcija, koje se kroz vreme menjanju, neke brže a neke sporije, kao što se menja i njihov broj, pa neke iščezavaju a neke nove se nenadano i nepredvidivo stvaraju tokom vremena. Ta promena funkcija, tačno bi bilo reći njihov hijerarhijski poredak i broj, uvođenje novih i nestanak starih, nije samo posledica promene konteksta iz koga se iščitavaju, već proističu i iz same prirode tvorevina koje promatramo. Nemaju samo jedno značenje ili svrhu. Umetnost u spoju sa praktičnom svrhom nalazimo na neočekivanim mestima, kao što su grbovnici, ili u izgrađivanju osobenog političko-religioznog diskursa u poeziji na istorijske teme. Analiza primera koji slede jeste građa iz koje se može sagledati kako umetnost funkcioniše u tome vremenu.

\section{Prvi primer}

Najpoznatija knjiga kod Srba i Hrvata u prvoj polovini XVIII stoleća bila je Stematografia... koju je sastavio Pavao Riter Vitezović i štampao 1701. g. u Beču, sa manjim izmenama 1702. u Zagrebu. Na podlozi drugog izdanja izrađena je Stematografija štampana u Beču 1741. g. po nalogu srpskog patrijarha Arsenija IV Jovanovića Šakabente, sa dodacima obima jedne manje knjige. Latinski tekst izvornika preveo je na ruskoslovenski (crkvenoslovenski) Pavao Nenadović, ${ }^{1}$ a bakrorezački rad obavio Hristofor Žefarović, uz pomoć Tomasa Mesmera (Thomas Messmer), u čijoj radionici je knjiga izrezana u bakru. Namera Riter Vitezovića u početku bila je izrada rodoslova i grbova istaknutih porodica kao dopunu rada o domovini i životu Ilira. ${ }^{2}$ U godinama posle Karlovačkog mira 1699. godine, a posebno u događajima koji su usledili zamisao se na bitan način menja. To je sada zbornik grbova teritorija kao dopuna istorijskim raspravama o hrvatskom pravu na Dalmaciju. To je razumljivo iz promenjenih okolnosti. Potpisanim mirom bilo je predviđeno da se novo razgraničenje između Austrije, Turske i Mletačke republike izvrši prema zatečenom stanju na terenu, tako što će svako da zadrži ono što je u tome trenutku posedovao. To se nije odnosilo na teritorije koje su bile na granici sa Hrvatskom, gde je trebalo ustupiti oslobođene teritorije, gradove i utvrđenja. To je izazvalo nezadovoljstvo koje je u formi protesta artikulisano u hrvatskom Saboru. Rezultat protesta bilo je uključivanje Ritera Vitezovića kao znalca hrvatske istorije u komisiju za razgraničenje grofa Marsilja (Marsigli). Tokom rada u komisiji Riter je u nekoliko navrata sastavljao spise sa istorijskom argumentacijom o teritorijalnim pravima Hrvatske. Konceptualno ti spisi sadržali su ono što je izložio u traktatu Oživljena Hrvatska (Croatia rediviva) objavljenom 1700. g. Spisi u kojima je dokazivao

\footnotetext{
Pisanje imena ličnosti XVIII veka nije standardizovano, često se arhaične forme modernizuju pa se Pavao ili Pavel menja u Pavle, ili prezime Georgijević u Đorđević, Georgije u Đorđe. To može da izazove zabune kao u ovome primeru jer je u istoj porodici budimskih Nenadovića postojao Pavle Nenadović i njegov sinovac Pavao Nenadović, čije ime kada se modernizuje dobijamo dve ličnosti sa istim imenom u istom vremenu i na istom mestu. Ovaj problem je rešavan, ponekad tako što se uz isti oblik imena dodavalo „mlađi“, odnosno „stariji“ ili neka druga odrednica. Dosledno sam se držao izvornih oblika imena, osim u slučaju Žefarovića. Slovo „ž“ služilo je u 18. veku za označavanje dva glasa: „dž“ $i$,žc, pa je njegovo prezime bilo Džefarović; da se ne bi stvorila zabuna zadržao sam ustaljeni oblik.

2 Prvi datum iz koga se pouzdano može videti Vitezovićeva namera jeste proglas iz 1696. godine: „Pošto sam poglavite časti svoga djela o žrtvenicima i ognjištima (tj. o domovini i životu) Ilira izradio, mišljah, da je vrijedno, prije ono na svijet iziđe, da skupim rodoslovlja odličnih porodica zajedno sa njihovim grbovima i slavnim činima, pa da ih u zasebnoj knjizi izdadem“ (Vjekoslav KLAIĆ, Zivot i djela Pavla Ritera Vitezovića, Zagreb 1914.,103).
} 
hrvatsko pravo na teritorije koje su pripale Mletačkoj republici privukao je pažnju Bečkog dvora. Naime, posle razgraničenja nastao je spor između Austrije i Mletačke republike zbog njenih teritorijalnih proširenja u Dalmaciji, tvrdilo se da su to delovi hrvatskog kraljevstva na koje Habzburzi imaju nasledno pravo. Dokazivanje naslednog prava imalo je funkciju legitimizacije ciljeva koji bi se ostvarili sa stanovišta moći. Ako je Dalmatinsko kraljevstvo postojalo u rimskom carstvu, onda je to teritorija na koju polaže pravo naslednik Rimskog carstva, ali ako to kraljevstvo nikada nije postojalo kao što je tvrdio Riter, već je to teritorija koja pripada Hrvatskoj, onda na nju pravno-istorijski imaju pravo Habzburzi. Zbog toga je Riter bio pozvan krajem 1700. godine u Beč da objasni teritorijalna prava Hrvatske, (a time i Habzburga) na primorje, zbog budućnosti. Tokom boravka u Beču Riter je izradio dva istoriografska spisa, koja su mu donela zvanje dvorskog savetnika. U tome kontekstu štampao je svoj ranije planirani grbovnik. Funkcija grbovnika bila je dopuna, dodatna argumentacija, istorijskih rasprava namenjenih habzburškom dvoru o hrvatskom istorijskom pravu na prostor koji je posle rata sa Turskom zaposela Mletačka republika, kao i na evropske teritorije Turske. Ti ciljevi su praktično-politički. Možemo ih označiti kao primarne. Ponešto drugačija akcentuacija je u drugom, zagrebačkom izdanju. U predgovoru pisao je: „Domovine, naime, sjaj u njima (grbovima) blista; sjaj kojim se svaki sugrađanin u svome rodu proslavljuje. Jer, kao što po junačkim delima otaca plemenštinu roda zadobivamo, tako i uvećanom domovinskom srećom većma slavni bivamo.3. Ovu funkciju možemo označiti kao sekundarnu. Grbovnik se uklapao u dva različita ali komplementarna konteksta: interese Habzburga i interese Hrvatske. U početku jedna rodoslovna koncepcija grbovnika značajnih porodica Ilirika, shvaćene kao države svih Slovena, preakcentovana je pod pritiskom određenih istorijskih okolnosti u praktično-političku koncepciju, da bi se u drugom izdanju akcentovala ideja o izgrađivanju nacionalne svesti kroz upoznavanje sa prošlošću. Od rodoslovske koncepcije u konačnoj verziji ostao je grb loze Nemanjića. Panslovenska ideja zadržana je u grbovniku preko grbova Rusije i Češke, kao delova Ilirika. Aktuelna politička ideja negiranja istorijskog postojanja kraljevstva Dalmacije (sužena je na nekoliko primorskih gradova) iskazana je uvođenjem grbova nepostojećih kraljevstava Jadrana, Dubrovnika i Istre.

Osnovni problem koji je u sastavljanju grbovnika Riter rešavao jeste, prvo, nedostatak grbova za teritorije koje je trebalo označiti i, drugo, postojanje dvojnih grbova i naziva za iste teritorije. Naime, u zvaničnoj habzburškoj terminologiji izbegavali su se nazivi za gradove, teritorije, etnonime, konfesije, koje je upotrebljavalo autohtono stanovništvo. Tako su umesto naziva mesta koje je upotrebljavalo stanovništvo koje je u njemu živelo imali Agram, a umesto Srbije, na primer, Ilirik, Tribaliju i Rašku. Umesto Hrvatske Croatiu, pravoslavni su bili grko-nesajedinjeni, a jezik kojim su govorili iliriko-rascijanski. Nametanje antičkih ili smišljanje novih naziva imalo je ideološku pozadinu. Ovakva praksa nije nepoznata ni kasnije, karakteristična je za kolonijalni diskurs. Izrečenom protivreči barem jedan, ali zanimljiv detalj. Postojao je grb Srbije sa glavom divljeg vepra probodne strelom. Koliko se to pouzdano može utvrditi pod tim nazivom prvi put se javlja u grbovniku Urliha Rihentala 1415. g. ${ }^{4}$ Potom su ga u XVII stoleću nosili članovi austrijske kraljevske porodice..$^{5}$ Od članova porodice Habzburga preuzet je za označavanje teritorija koje pripadaju

Citirano prema: Ivo BANAC, Grbovi, biljezi identiteta, Zagreb 1991., 121.

A. V. SOLOVJEV, Istorija srpskog grba, Melbourne 1958., 48.

Vidi: Arthur C. FOX-DAVIES, The Art of Heraldry, an Encyclopedia of Armory, London 1986. (prvo izdanje 1904).

$\mathrm{Na}$ tabli CVIII nalazi se reprodukcija "Grb stare Srbije“ - veprova glava probodena strelom. Za ovaj grb kaže se da 
Ugarskom kraljevstvu, u nizu drugih. Riter je, tako, u ovome slučaju imao dva različita grba - glava vepra i krst sa ocilima - sa istim naslovom. Jedan se upotrebljavao u nemačkim grbovnicima, a drugi je bio u domaćoj tradiciji, nalazio se u Orbinijevom delu $I l$ regno degli Slavi (1601.). U ovome slučaju Riter je dao prednost domaćem izvoru, grb sa veprovom glavom preimenovao je u grb Tribalije. Nastojeći da uskladi različite interese Riter je za iste teritorije uglavnom koristio dvojne grbove i nazive. Tako za grb Rame kaže: „Tim imenom ugarski kraljevi podvode pod kraljevski naslov Bosnu, Hlivno, i Hercegovinu". ${ }^{6}$ Riterov zbornik osoben je po tome što je u njega uključio grbove i nazive za teritorije koje je za označavanje sopstvenog identiteta koristilo autohtono stanovništvo. Davao ih je naporedo.

Kolikogod da je grbovnik u funkciji težnji pravno-političke priorode, on je još i zanimljivo i vredno umetničko delo, književno i likovno. To se najbolje primećuje u glosama za grbove. Grbovi u zborniku imaju trodelnu strukturu, kao da su emblemi: natpis, sliku i pesmu. U sastavljanju grbovnika to je pre izuzetak nego pravilo. Pesma (subscriptio) sadrži tumačenje semantike likovnog dela grba i pojma iskazanog u naslovu (u ovome slučaju nazive teritorija). Prva dva stiha su deskripcija slike, druga dva su poentna - objašnjava se njihovo značenje. Postupak kojim je Riter osmišljavao značenja grbova najpre se može povezati sa teorijom umetničkog stvaralaštva baroka. Cilj je bio da se iskaže suština slikom označenog prostora radom ingenioznog uma koji će povezivanjem udaljenih pojmova prozreti njegovu suštinu, a čitaoca zaprepastiti, odnosno začuditi, takvim neobičnim povezivanjem. U tu svrhu Riter je upotrebio tri karakteristična manirističko-barokna postupka: končetistički metaforizam, anagramiranje i fantastične „etimologije“. Tako je grb Ilirije protumačen kao spoj velikih mogućnosti (šestokraka zvezda) i zle sreće (mesec). (Ono što je pozitivno smešteno je gore, negativno - u donji deo grba). Na istom principu je protumačen i grb Nemanjića: dvoglavi orao u poletu u središnjem, gornjem delu grba, simbolizuje moć i uspeh koji je pomućen fatalnim krinovima u donjem delu grba koji mu vezuju noge i sprečavaju polet. Grb Rame sa rukom koja drži isukanu sablju (treba primetiti da je ruka okrenuta na desnu stranu, što konotira pozitivno značenje - oružje upereno u odbranu od neprijatelja - leva i desna heraldička strana određuju se iz obrnute perspektive), protumačena je anagramiranjem reči Rama: Arma (oružje). Tako ova teritorija svoju sudbinu nosi (skrivenu) u svome imenu. Na sličan način su pravljene i „etimologije“. Iz slučajnog sazvučja reči izvodi se zaključak o suštini pojma koji označava. Riter ju je upotrebio u tumačenju grba Srbije. Reč „Serbia“ u sazvučju je sa rečju „servia“ (serv, rob, robovanje) pa je otuda i sudbina Srbije tako objašnjena: „Srbija nosi kao znake krst i ognjila u crvenom polju; za krst je ona pretrpela mnoge vatre. Sad kada je krst oboren, ona podnosi još (nove) udarce. Stoga po sudbini i stvarno nazvana Servijom “" 7 Ovakvo tumačenje ponovljeno je u proznom komentaru na kraju knjige: „Udesom sudbine je ovaj simbol dopao Srbljima, jer oni, pošto su dugo i često bili napadani radi hrišćanskog oltara i rodnog ognjišta, dopadoše u tužno ropstvo“. .8 Ovde se „etimologija“ povezuje sa idejom stradanja zbog vere. Nisu svi grbovi protumačeni u ovome maniru, neki od njih su naprosto deskriptivni: grb Raške sa potkovicama znači da tamo ima mnogo željeza i kovača. U svim slučajevima uvek se težilo da se na stilski neobičan ili manje neobičan način iskaže suština prostora koji je grbom označen

su ga nosili članovi austrijske kraljevske porodice. Izrađen je na početku 17. veka (između 1602. i 1618) u stilu nemačke renesanse.

I. BANAC, Grbovi, 127.

A. SOLOVJEV, Istorija srpskog grba, 37-38.

Isto, 16. 
polazeći od imena i slike, ili samo od imena, ili samo od slike. Riterov zbornik koliko je po intenciji istorijsko-pravno-politički spis, toliko je i umetnička tvorevina.

Kada je četrdeset godina kasnije objavljen u srpskoj verziji, sa tačnom naznakom predloška izdanja po kome je rađen, zadobio je drugi smisao i cilj. To je bilo uslovljeno drugačijim istorijskim kontekstom; drugačijim pravno-političkim položajem Srba u Habzburškoj monarhiji od onoga koji su imali Hrvati; delovale su i posebne okolnosti u kojima se nalazio poručilac posla, i finansijer, Arsenije IV. To je vreme posle druge seobe Srba (1738. g.) pod Arsenijem IV Jovanovićem Šakabentom. Pre drugog talasa seoba mitropolijsko-patrijaršijski presto u Sremskim Karlovcima bio je upražnjen od 1737. godine. Dolaskom pećkog patrijarha Arsenija IV pitanje izbora novog patrijarha bilo je interno rešeno, ali je bila potrebna potvrda Habzburškog dvora. To nije bio jedini problem koji je trebalo rešavati. Osim potvrde na mestu mitropolita i prava da zadrži naziv patrijarha, postojala su još dva bitna zahteva: potvrda privilegija i kanonsko pravo na svim teritorijama gde su živeli vernici.

Obnovljeno i prošireno izdanje Riterovog heraldičkog zbornika u njegovoj ruskoslovenskoj (crkvenoslovenskoj) verziji bilo je namenjeno unutrašnjem mnjenju, kao što je to bio i prevod privilegija sa latinskog jezika na ruskoslovenski objavljen 1745. g. Latinski je bio jezik habzburške administracije, pa prema tome i sredstvo komunikacije sa njom; crkvenoslovenski je zvanični jezik crkve, u tome vremenu i nauke, i književnosti.

Tako knjiga ima više funkcija. Da je Riterov grbovnik mogao u potpunosti odgovoriti svim potrebama ne bi imao ono što nazivamo njegovim „dodacima“. To su: utvrđivanje položaja crkve unutar korpusa kao neprikosnovene uprave u svetovnim i crkvenim pitanjima; utvrđivanje položaja Arsenija IV; integracija drugih etnikuma hrišćanske verospovesti koji su u seobi došli zajedno sa Srbima; ukazivanje na drevnu državnu prošlost koja treba da osnaži političke zahteve u sadašnjosti; buđenje svesti o staroj državi koju treba obnoviti. Objavljivanje zbornika bio je pogodan način da se vizuelnim sredstvima nepismenom stanovništvu prenesu ideje.

Neprikosnoven položaj crkve unutar korpusa kao neke vrste teokratske uprave u svim pitanjima (uključujuči tu i imenovanja graničarskih oficira) bio je osporavan od samih početaka življenja u Habzburškoj monarhiji. Osporavaju ga vojnički stalež i u tome vremenu već formiran građanski stalež sastavljen od zanatlija i trgovaca. Od samog početka, odmah po preseljenju, na narodno-crkvenom saboru u Budimu 1691. postavljen je zahtev za postojanjem svetovne uprave odvojene od crkve, a za srpskog despota zatraženo je da se imenuje grof Georgije Branković. Tome se suprotstavio Arsenije III koji je tražio i svetovnu vlast za sebe. Beč je sledeći svoje interese svetovnu upravu predao crkvi. Centar otpora neprikosnovenoj crkvenoj unutrašnjoj upravi bio je u Budimu; premeštao se tokom XVIII stoleća sve više u Novi Sad.

U tome smislu prevođenje istorijskih vladara u svece ne znači samo slavljenje državne prošlosti u funkciji političkih ciljeva usmerenih prema budućnosti, već i prevođenje svetovne istorije u crkvenu. Crkva je nosilac i produžetak stare srpske državnosti. Ono što su nekada bili vladari, to su sada crkveni velikodostojnici, pa se tako u nizu portreta ispred Stematografije, pored vladara-svetaca i crkvenih svetaca, pomešanih, na kraju javlja portret Arsenija IV Jovanovića Šakabente kao poslednji u nizu. To je trebalo da unutar korpusa utvrdi poziciju crkve kao presonalne uprave preseljenog naroda, u svetovnim i crkvenim stvarima, i Arsenija IV kao njihovog sadašnjeg poglavara. Iza slike su dve posvetne pesme Arseniju IV, jedna u formi magičnog kvadrata sastavljenog od slova koju je potpisao Hristo- 
for Žefarović, i nepotpisane posvetne pesme (140 parno rimovanih poljskih trinaesteraca). Ideje iskazane slikama, u pesmi su artikulisane rečima.

Implicitno prvi deo knjige istovremeno izražava i jedan koncept uslovno rečeno „nacije“ zasnovan na religioznoj pripadnosti. Svi koji su pravoslavni jedan su narod. Ali, u njemu nisu zastupljeni samo oni koji su pravoslavni već i Albanci katolici koji su u seobi došli zajedno sa Srbima pod istim uslovima, i naselili se sa njima na istom prostoru. Vidljivo je to, po unošenju u prvi deo knjige pored pravoslavnih svetaca i vladara svetaca i dva katolička sveca zaštitnika čiji su kultovi postojali kod preseljenih Albanaca. Tu su i sveci čiji je kult postojao kod Bugara. Ovde se politički pragmatizam ukršta sa religijom. Takav je bio sastav preseljenog stanovništva. Bugari su sa Srbima stigli još u prvoj seobi sve do Sent Andreje. Ovakav oblik svesti o zajedništvu - verska pripadnost je hijerarhijski iznad etničke i jezičke - trajao je sve do prvog dela druge polovine XVIII stoleća kada se uvodi iz Evrope importovana ideja o naciji kao zajednici koja govori istim jezikom (eksplicitno Dositej Obreadović u spisu Pismo Haralampiju, 1783. g.), mada se ovakav oblik svesti o identitetu zadržao i kasnije. To bi mogle biti najvažnije funkcije prvog dela knjige.

Riterov grbovnik je drugi, ujedno i najobimniji deo zbornika. Njegova funkcija je slična onoj koju smo kod Ritera označili kao sekundarnu: ukazivanje na prošlost radi ostvarivanja ciljeva u budućnosti; razvijanja svesti o staroj državi, pa prema tome i težnji da se ona obnovi. Izvršena je zamena, umesto hrvatskog Ilirika sada je to Dušanovo carstvo. To je jasno po položaju bakroreza koji prikazuje cara Dušana sa vencem grbova teritorija koje su ulazile u njegovu državu. On je umetnut iza naslovne strane Stematografije, a ispred grbova Ilirije i doma Nemanjića. Ova tri grba su izuzeta iz abecednog poretka ostalih grbova.

Treći deo, ono sa čime se završava knjiga, manje je značajno od prethodna dva dela; nema ideološke ili političke konotacije. To je pesma, po vrsti oda, Pavela Nenadovića posvećena Hristoforu Žefaroviću, a poslednji list je prikaz lika Stefana Nemanje. Ova dva priloga su zanimljiva po sebi, a u sklopu celine donekle i odudaraju, ili su čak nesaglasni osnovnoj intenciji knjige. Kompozicioni postupak sa prigodnim ili „zabavnim“ završetkom ima paralelu i u Riterovom gbovniku. ${ }^{9}$ On nije neuobičajen u komponovanju knjiga starijih perioda, na kraju se daju raznovrsni sadržaji zabavnog ili poučnog karaktera. Ponekad su imali naslov „smesice“. Tako Nenadović objavljuje pohvalnu pesmu bakrorescu zbornika Žefaroviću u pseudosapfijskoj strofi, tj. sapfički jedanaesterac zamenio je poljskim trinaestercem, dok je zadržao sapfički peterac u epodi. Poljski trinaesterac je stih čitave knjige: njime su prevedeni Riterovi heksametri i napisane obe pesme. Ovaj stih ima zanimljivu istoriju: francuski aleksandrinac je u poljskoj književnosti adaptiran u trinaesterac, otuda je prešao u rusku književnost, iz nje u srpsku na početku 18. veka. U tome vremenu smatran je drevnim slovenskim stihom. Klasična sapfička strofa se, pak, osećala kao strana forma. Naime, u tome vremenu u ruskim prilikama uvođenje klasične prozodije i klasičnih strofa imalo je značenje emancipacije od crkve, odnosno njenu modernizaciju. Ovde se izbegla upotreba forme koja se osećala kao strana i nesaglasna crkvi . U tome vremenu upotreba klasičnih strofa bila je ograničena na školsku edukaciju u slaveno-latinskim kolegijima osnovanim tridesetih godina. Tako se strana forma ispunjava stihom iz slovenske tradicije, ali ne u potpunosti. Završni stih strofe,

\footnotetext{
Pohvalna pesma sastavljaču grbovnika postoji i kod Vitezovića u prvom, bečkom izdanju knjige. Napisao ju je Nicolaus Garzia de Londonio i u njoj rekao „da bi književni svijet morao Ritera radi toga djela s punim pravom poštovati“(V. KLAIĆ, Život i djela P. R. Vitezovića, 153.). Nešto slično tvrdi i Pavao Nenadović za Žefarovića koji je u bakru gotovo sam izrezao knjigu: „Ot naroda štušta se čest že i pohvalu / i imeti budeš pamjat no ne malu“ (Stematografia, 54; fototipsko izdanje u: Dinko DAVIDOV, Srpska Stematografija, Novi Sad 2011.).
} 
peterac, gradi sličnost sa formom sapfičke strofe, na osnovu njega i predpostavljamo da mu je to bio model po kome je pisao. Ovaj postupak pokazuje kulturološku poziciju: strana forma se modifikuje tako što se adaptira na domaće metričke oblike.

Poslednja stranica knjige sadrži portret Stefana Nemanje (tj. cara Dušana) u baroknom ovalu sa prikazom peščanog sata i alegorijskih figura Hronosa i Minerve. U donjem delu bakroreza je tekst: „Vsja sueta“. To je citat iz Biblije, a poglavlja odakle je citat uzet označena su slovima. Tradicionalna upotreba slova za označavanje brojeva veoma se dugo zadržala u srpskoj kulturi, još u prvim decenijama XIX stoleća, naporedo sa upotrebom brojeva i, ređe, latinskih slova u značenju broja. I godina rezanja na naslovnoj strani Zefarović-Nenadović-Mesmerove Stematografije data je dvojako, arapskim brojevima i slovima sa odgovaraju-

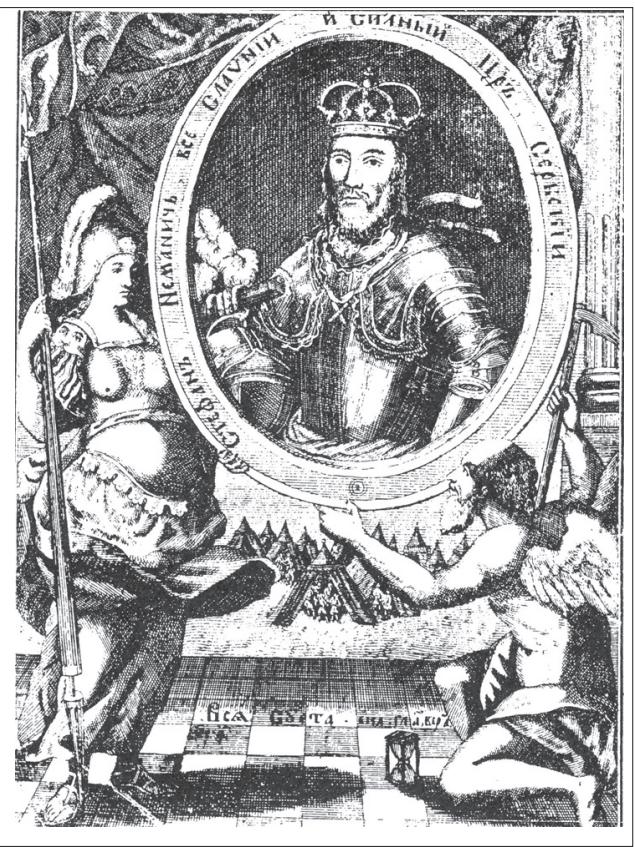
ćom brojčanom vrednošću, na taj način su paginirani i bakrorezni listovi. Citat potiče iz Knjige propovednika gl.1, 2 koji u Daničićevom prevodu glasi: „Taština nad taštinama, veli propovjednik, taština nad taštinama, sve je taština“. Peščani sat je poznati barokni motiv vanitas, znači prolaznost vremena. Poruka je moralistička. Kombinacija lika slavnog vladara sa ukazivanjem na besmisao slave pred smrću istovremeno slavi i snižava veličinu ukazivanjem na njenu prolaznost. Tako na slici imamo spajanje protivnosti, odnosno končeto. To je varijacija na temu memento mori. Poslednja strana knjige istovremeno je i u antitetičkom odnosu sa prethodnim stranicama knjige, kao njegova poenta, neočekivani zaoštreni završetak. Ona se mogla pojaviti u poslednjem, trećem delu zbornika, jer je on oslobođen stege ideološko-političkih zahteva. Više služi zabavi, razonodi. Namenjen je „nižim“ temama, kao posveta, pohvala, iskazivanju tipično baroknog pogleda na svet pa i ako je on nesaglasan osnovnoj intenciji knjige.

Kompozicija knjige je složena, ima tri različito oblikovana dela. Oni zajedno čine jednu artificijelnu, slojevitu, višeznačnu celinu. Mešaju se različite ideje, likovni jezici, stilovi. Tradicionalni stil freske ili ikone prenet je u bakrorez, naporedo sa baroknim stilskim obradama vladara i svetaca. Mešaju se i na istoj slici. Klasicističke strofe adaptiraju se na stihovnu formu crkvene tradicije. Ideologija crkve kao nosioca stare državnosti i težnje za njenom obnovom, susreće se sa baroknim pogledom na svet o prolaznosti i ništavnosti takvih težnji. Možda bi se u traženju adekvatne oznake knjiga najpre mogla nazvati zbornikom, zbog svoje kompozitnosti.

Žefarović-Nenadović-Mesmerov zbornik jedna je od najlepših knjiga štampanih kod Srba u tome vremenu. Bila je i ostala estetski predmet. Razlog tome nije u težnji da se umetnički i zanatski stvori nešto reprezentativno, već zbog nepovoljnih okolnosti. Bakrorezne knjige su bile skupe, u tome vremenu smatrane su luksuzom. Kod Srba ih ima u odnosu na ekonomsku moć nesrazmerno puno jer je to bio gotovo jedini način da se knjiga štampa. Štamparije sa ćiriličkim fontom nisu bile dostupne, bilo ih je malo, bile su udaljene, i nisu stalno radile. 
Dalja recepcija ove knjige bila je najrelevantnija u njenom grbovnom delu - odredila je grbove Srbije, Hrvatske, i Bugarske. Imala je odjeka kod Rumuna. Zbog toga se, verovatno, ova slojevita i kompoziciono zanimljiva knjiga prevashodno vidi kao zbornik grbova, njene ostale funkcije su se izgubile - ostale su zarobljene u vremenu objavljivanja.

\section{Drugi primer}

1750. godine Joakim Marković (rođen i školovan u Budimu, slikar i knjižar) naslikao je za ikonostastas crkve u podravskom selu Plavšnici dve istorijske slike. Jedna je prikaz Srbina

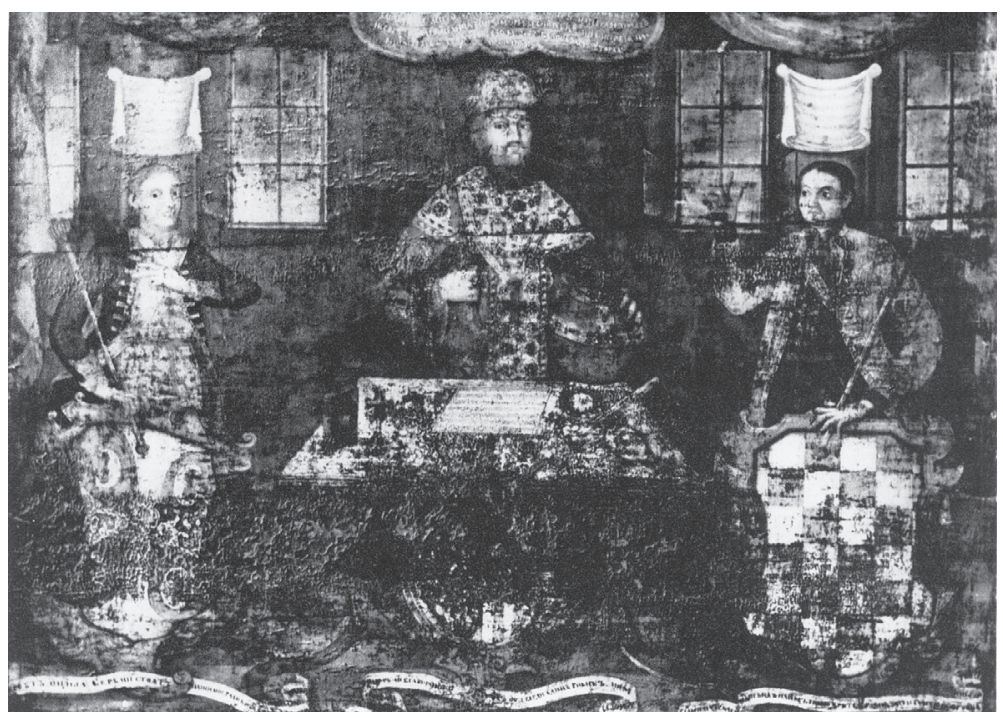

Srbin i Hrvat primaju privilegije od vizantijskog cara

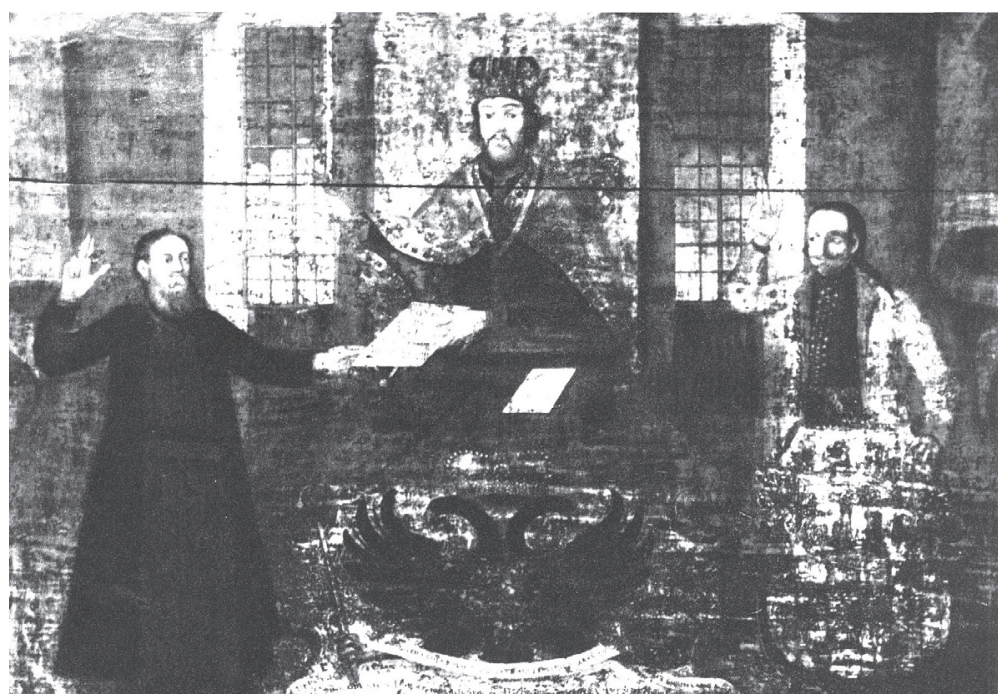

Srbi primaju privilegije od Rudolfa II 
i Hrvata kako primaju privilegije od vizantijskog cara Vasilija Makedonskog po doseljenju. On ih prima na svoju teritoriju i dodeljuje im povlastice. Prema tekstu koji je na slici, da upravljaju, sude, i žive na prostoru koji nasele. Druga slika prikazuje krajiškog oficira koji drži štit na kome je kombinaciju srpskog grba i grba Kroacije iz Stematografije, i pravoslavnog sveštenika, kako primaju privilegije od habzburškog Rudolfa II 1612. godine.

Politički kontekst ovih slika čini se jasan, kao i njihova poruka. To je vreme borbi oko privilegijalnih prava. U vreme mira lokalno plemstvo pokušavalo je da ih prevede u kmetove; u vreme ratova kada su krajišnici bili potrebni na ratištima Evrope, prava su obnavljana, i poštovana. Njihovo postavljanje u crkvu, među oltarske ikone, sasvim nekanonski, imalo je značaj snažne poruke usmerene prema graničarima u cilju razvijanja i podsticanja njihove svesti o posebnosti njihovog statusa, i njegove pravne zasnovanosti. Oslonac za prvu sliku bila je Baronijeva (Baronius) istorija crkve, knjiga koja je u duhu težnji reformacije prikazivala istoriju crkve kao istoriju ljudi, ali sa teološkom pozadinom. U tome smislu Baronijeva istorija je nazivana građanskom. Knjiga je u srpskoj kulturi bila poznata, i Dositej Obradović u svojoj autobiografiji kaže da ju je čitao u Hopovu, te da je ona bila jedan od faktora njegove preorijentacije od srednjovekovno monaških težnji ka klerikalnoj prosvećenosti. Ovde je upotrebljena kao istorijski izvor, deo iz nje je citiran. Na ovoj slici, međutim, primanje hrišćanstva je sekundarno - istaknuto je dobijanje privilegija po preseljenju. Druga slika, koja takođe obiluje tekstom, za podlogu ima privilegijalne povelje koje se bile iluminirane. Iluminacije na poveljama, smatra se, ${ }^{10}$ bile su osnova ikonološkog rešenje druge slike. Slike su bile zasnovane na istorijskom znanju onoga vremena, ali je postupak povezivanja dva događaja nemoguće razumeti bez poznavanja tipološkog simbolizma. U ovom tumačenju koje je specifično razvijeno u okvirima patrističke egzegeze jedan događaj u Starom zavetu je figura događaja u Novom zavetu. Na primer, Adam, Mojsije, Ješua u Starom Zavetu su figura pojave Hrista u Novom Zavetu. Od obične, alegorije ova tipološka alegorija (ili figuracija) razlikuje se po tome što se jednom značenju dodaje drugo („ovo i ono“), pa Adam, Mojsije i Ješua iako su figure Hrista ostaju ono što jesu, dok se u pesničkoj alegoriji jedan znak zamenjuje drugim, obično neki konkretan sa apstraktnim značenjem (crkva se koristila i ovakvim alegorizmom, npr. opis proleća je alegorija Hristovog rođenja; „ovo umesto onog “). Tipološki alegorizam (ili simbolizam - jasna razlika nije se pravila pre pojave romantizma) kombinuje hronologiju sa uzročnošću - događaji koji dolaze imaju svoj uzrok u svetoj knjizi koja providencijalno određuje sudbinu svega onoga što će biti. Bitno je istaći da se u ovom tipu alegorizma događaji koji se povezuju smatraju istinitim, odnosno istorijskim. Zbog toga se ovakav tip alegorizma naziva još i alegorija in factis, prema pesničkoj alegoriji koja je in verbis. Ovaj metod primenjivao se i od samih crkvenih autoriteta u tumačnju svetske istorije, time se ona nastojala uključiti u istoriju crkve. U kasnijem razvoju postupak tipološkog simbolizma primenjivao se na sekularnu istoriju, da bi od XVII stoleća bio korišćen za moralističke i političke ciljeve.

$\mathrm{U}$ tome smislu primanje privilegija graničara od Habzburga je prefiguracija primanja privilegija od vizantijskog cara. Odnosno, primanje privilegija na prvoj slici jeste figura ili tip događaja na drugoj slici. Zbog toga što je događaj istorijski, dakle istinit, on se prikazuje „realistički“. Istorija zastupljena na slici ne postoji na onaj način na koji je mi danas

10 Vidi: D. MEDAKOVIĆ, „Dve istorijske kompozicije slikara Joakima Markovića iz 1750”, u Putevi srpskog baroka, Novi Sad 1971., 89-91. 
shvatamo, kao što ni realizam nije najpodesniji izraz za prikazivanje „realnih“ detalja koji se mogu uočiti. Tako zbog razlika $\mathrm{u}$ istorijskom vremenu postoje i razlike u organizaciji slike, i upotrebi „realističkih“ detalja. To se može pratiti na više nivoa . Na prvoj slici neutralisana je opozicija leva strana (negativno) - desna strana (pozitivno), obe strane su pozitivne; na drugoj slici ta razlika se sa svojim semantičkim potencijalom jasno uspostavlja, zaklinjanje se obavlja dizanjem desne ruke. Kostimi iz XVIII stoleća u kojima Srbin i Hrvat primaju privilegije od vizantijskog cara mogli bi se već nazvati pseudoistorijskim, takvim se može shvatiti i zaklinjanje sa tri prsta. Naime, na prvoj slici i Srbin i Hrvat se zaklinju tako što podižu ruku sa tri rastavljena prsta, što označava sveto trojstvo. Zaklinjanje, kao i krštenje sa tri prsta jeste pojava iz postvizantijskog perioda nastala u grčkoj crkvi. U Vizantiji je postojalo čvrsto pravilo krštenja i zaklinjanja na onaj način na koji je to činio Isus, sa dva prsta. To je pravilo važilo i u Rusiji sve do XVIII stoleća, kada je administrativnom merom uvedeno krštenje sa tri prsta uz veliki otpor staroveraca. Smatra se da je taj običaj u Rusiju stigao u tzv. drugom talasu južnoslovenskog uticaja, u čemu je, po svemu sudeći prvi tu novinu praktikovao Grigorije Camblak, bugarsko - srpski pisac i monah. ${ }^{11} \mathrm{Na}$ drugoj slici, „realistični“ su opanci na nogama sveštenika koji prima od Habzburga privilegiju. $\mathrm{Na}$ istoj slici prepoznaje se još jedan „realistički“ detalj na simboličkom nivou. Srbi, graničarski oficir i sveštenik, dva prsta drže spojenim, treći je odvojen. Prema teološkoj doktrini u pravoslavnom učenju otac, sin i duh su ravnopravni, dok u katoličkom hrišćanstvu otac i sin proishode iz sv. Duha. To je krucijalna razlika, u učenju ovih hrišćanskih crkvi i važan predmet spora. Pristupanje uniji simbolično je iskazano položajem prstiju. Treba naime znati da je najzapadnija pravoslavna eparhija zbog specifičnog položaja uz saglasnost, a možda i na preporuku, pećkog patrijarha prihvatili uniju u određenom, ograničenom obliku. Priznala je Papu i katoličku crkvu za vrhovnog poglavara, ali je zadržala autonomiju u izboru sveštenika, predlaganju episkopa koji je i dalje potvrđivan od srpskog Patrijarha, ali i od Pape, a na kraju od Habzburga. ${ }^{12}$ Ovakav, i slični oblici poluunije, ili prihvatanja određenih simboličkih obeležja i učenja katoličke crkve, prisutni su u Karlovačkoj mitropoliji na više nivoa, od simboličkog (npr. patrijaršijski grb ima plaštanicu, što je obeležje unijatskih grbova), do više suštinskog.

Stil Joakima Markovića bio je, kako je tačno primećeno „sa izrazitim osobinama kombinacije zapadnog i istočnog stila“. ${ }^{13}$ Mogli bismo to terminološki preformulisati u spoj modernog i tradicionalnog. Obe slike su plošne: prostor se prikazuje oko objekata a ne obrnuto, objekti u prostoru. Da bi to bilo potpuno jasno treba uporediti minijaturu na privilegijalnom dokumentu koja se smatra mogućim predloškom slici sa istorijskim prizorom iz novijeg doba. ${ }^{14} \mathrm{~S}$ druge strane prikazuje se pokret, što je netipično za tradiciju. Tradicionalno je po svome poreklu unošenje tekstova na sliku. Ali, sa druge strane, tekst je upotrebljen na način netipičan za tradicionalno freskoslikarstvo. Svoje ime slikar je upisao u tekst na slici tako što je pojedina slova markirao crvenom bojom. Kada se razasuta markirana slova čitaju povezano dobija se ime slikara. Isto je ponovio i na slici sa scenom iz novijeg vremena, samo je imenu dodao i zanimanje: „moler“ ${ }^{15}$ Šifrovani potpisi su u prvoj

\footnotetext{
11 Vidi B. A. USPENSKIJ, „K istorii troeperstija na Rusi”, u Etjudy o russkoj istorii, Sankt-Peterburg 2002., 361-370.

12 R. GRUJIĆ, „Pakračka eparhija, istorijsko statistički pregled”, u Spomenica o srpskom pravoslavnom vladičanstvu pakračkom, Pakrac 1930., 47-48., i dalje.

13 Isto, 111.

14 Vidi reprodukciju u nav. radu D. Medakovića.

15 Opis svih natpisa na slikama uradio je Fedor Moačanin. Vidi: D. MEDAKOVIĆ, Putevi, 86-87.
} 
slici upisani u tekst koji je u gornjem delu slike na njenoj ivici, na drugoj slici potpis je unet u tekst koji govori ktrajišnik, i on je na njenom donjem kraju. U potpisivanju očigledno postoji težnja ka određenom smišljenom rasporedu, dakle i estetskom delovanju. Šifrovani potpisi uokviruju obe slike, zatvaraju prikazane scene prema gore (početak), i prema dole (kraj). Tako šifrovani potpis zadobija kompozicionu funkciju. Način na koji je unet u sli$\mathrm{ku}$ - isticanjem rasutih slova crvenom bojom čije povezano čitanje daje ime - naziva se, onda kada se javlja u poeziji, Versus gryphici. ${ }^{16}$ Ovakav stilski postupak najpre se i nalazi u baroknoj književnosti i njoj srodnim periodima po težnji ka artificijelnosti. Za još jednim manirizmom posegao je Marković na ovoj slici. Govor cara i krajišnika pisao je s desna na levo, a pojedina slova napisao je kao da su u ogledalu. ${ }^{17}$ To sugeriše ideju da dodatnu poruku i smisao trebamo tražiti u palindromnom, „račjem“ čitanju reči. Barokni stil i pogled na svet u ovim slikama susreo se sa srednjovekovnom tradicijom u postupku figuracije i pojedinim elementima stila.

\section{Treći primer}

Zaharije Stefanović Orfelin štampao je u Veneciji 1761. godine pesmu Gorestni plač, kao knjižicu, koja je ubrzo posle objavljivanja gotovo u potpunosti uništena; do nas je stigla u sačuvanom prepisu. Jezik je ruskoslovenski, a forma sesta rima sa pridodatim nerimovanim stihom. To je, koliko se može pouzdano znati, prvi poznati primer upotrebe ovog tipa strofe u srpskoj književnosti. Po sadržaju to je plač, kako stoji u naslovu, Srbije nad svojom istorijskom sudbinom - nekada je bila slavna država, a sada je narod rasut i porobljen sa neizvesnom budućnošću. U 26 strofa tema se postupno razvija dodavanjem pojedinosti do zaokruženosti opisa sadašnjeg stanja u opreci prema nekadašnjem. Tema pesme nije bivša slava i plač za njom, već plač nad savremenom situacijom u čiji opis je utkana kritika onih koji su do toga doveli. U ovoj pesmi Orfelin je uspostavio analogiju između seobe Srba u Austriju sa nasilnim preseljenjem jevrejskog naroda iz Judeje u Vavilon opisan u Starom zavetu. Orfelin je fusnotama uz 4, 5, i 10. strofu povezao tekst svoje pesme sa delovovima iz Plača proroka Jeremije i Knjige proroka Jezikilja iz Starog Zaveta. Težak život u tuđini i tugovanje za postojbinom tema je biblijskih psalama na koje Orfelin ukazuje. ${ }^{18} \mathrm{Za}$ ilustraciju postupka biće dovoljno navesti petu strofu i fusnotu uz nju:

Predjeli ridajut
Serbskiji preslavni
Čto ne proježajut
Voni vshvalni:
Gradi razoreni
Vsi opustošenni,
Kako da ne plaču. ${ }^{19}$

16 Dmitri ČIŽEVSKI, „K problemam literatury barokko u slavjan”, Litteraria, XIII/1971., 36.

17 Prema opisu Feodora Moačanina :"Tekstovi koje govore Krajišnik i car pisani su zdesna nalijevo. Pojedina slova iskrenuta su kao u ogledalu“, op. cit. Na snimku slika ne mogu da se uoče opisani detalji.

18 Napomene se nalaze posle četvrte strofe, a upućuje se na Plač Jer. Gl.5, 13,16,17; iza strofe 5, ima uputstvo „zri pri koncu knjižici“, gde se nalazi jedna beleška i ukazivanje na Plač. Jer. gl. 5, st. 2,12,15,17; na kraju strofe 10, ukazuje se na Plač. Jer, 2, 14. Jez. 34,5,8.

19 Navedeno prema Mladen LESKOVAC, Antologija starijeg srpskog pesnisttva, Novi Sad - Beograd 1964., 294. 
Beleška koja dolazi iza pete strofe (samo je štampana na kraju pesme) glasi: „Obidajušči prosivaše Serbskoga Knjaza (Despota) Gosudarja Georgija Brankovica izvesti narod svoj i v pomošt im biti protiv Turkov, jegože tak sotvorša, prelešteniem i obmanojut pohitili, i v zatočenie postavši jego, idježe boljeje ... ljet prebiv život sij skončal“ ${ }^{20}$ Iza beleške sledi ukazivanja na Plač Jereminijin stav 2, 12. : „Knezove vešaju svojim rukama, ne poštuju lica staračka“. Uspostavljena je veza između sudbine biblijskih kneževa i Georgija Brankovića. Ponovo se susrećemo sa tipološkim simbolizmom u funkciji političkih borbi.

Nije u ovoj pesmi i njenim komentarima toliko sporan iskaz o nezadovoljstvu životom u Habzburškom carstvu, ili kritika crkvene uprave, ni uspostavljena analogija, koliko beleška u kojoj se ukazuje na sudbinu nesuđenog despota Brankovića. To je bio iritantan politički momenat. Koliko je tema Brankovićeve sudbine bila značajna i politički nepoželjna za pominjanje, pokazuje još jedan događaj iz iste godine, na istom mestu, $i$ tesno povezan sa pominjanjem Brankovića u Orfelinovoj pesmi.

Naime, Pavle Julinac, viši oficir habzburške vojske, boravio je istovremeno kada i Orfelin u Veneciji. Došao je da nadgleda štampanje svoje knjige Kratkoje vvedenie v istoriju proishoždenija slaveno-serbskago narod, za koju je napisao predgovor. U predgovoru iskazao je nezadovoljstvo životom u novoj državi. U tome kontekstu posebno je naglasio slučaj grofa Georgija Brankovića - Habzburzi su ga priznali za narodnog vođu dok je dizao narod na rat protiv Turaka, a kada im više nije trebao - internirali su ga. ${ }^{21}$ Oba teksta, Orfelinova pesma sa komentarima, i Julinčev predgovor istorijskom spisu po intenciji su gotovo isti, nastali su u isto vreme i na istom mestu, a imali su i isti ishod: $u$ fazi početne distribucije cenzurisani su. Štampar Dimitrije Teodosije, nakon što ga je neko upozorio ili reagovao na prve distribuirane primerke, obustavio je dalju distribuciju, tiraž Orfelinove pesme uništio, a Julinčev predgovor zamenjen je drugačije napisanim, po tonu i nameri. U tom izmenjenom predgovoru, Julinac piše da je Srbima u Habzburškoj monarhiji dobro, jer imaju Privilegije. Na kraju knjige štampan je prevod Privilegija u izvodu. Time se ova knjiga uklopila u već ranije borbe za očuvanje privilegijalnog statusa, približno na isti način na koji je to činio i Joakim Marković u svoje dve istorijske slike. I Orfelin je ponovo napisao pesmu sa istom temom, gotovo na narodnom jeziku, u drugoj metričkoj i strofičnoj formi. Pesma je zadržala kritičko usmerenje, ali bez analogije sa biblijskom istorijom i famozne beleške o Brankoviću.

Prizivanje Brankovića, imalo je u tome vremenu značenje jedne političke opcije koju je simbolizovao: težnju da se zasnuje država sa sekularnim vladarem. Koliko se pouzdano može rekonstruisati kod Srba su postojale tri struje: pro-ruska čije glavne reprezente vidimo u Parteniju Pavloviću, kasnije u Dionisiju Novakoviću i Visarionu Pavloviću - njihova glavna akcija bila je osnivanje Latinističke škole u Petrovaradinskom šancu (Novom Sadu) i Duhovne akademije koja je kratko trajala, zbog zabrane. Druga struja bila je pro-austrijska (nemačka); treća - stvaranje samostalne države sa sekularnim vladarem. Ovoj trećoj opciji među istaknutim intelektualcima inklinirali su Zaharije Orfelin i Pavle Julinac. Ova poslednja opcija bila je u neskladu sa politikom crkve i austrijskog dvora, zbog toga nam je i jedva poznata, skrivena, i teško prepoznatljiva - svaki glas ovakve vrste sistematski je cenzurisan.

20 Mladen LESKOVAC, Antologija., 297.

21 Vidi „Pogovor“ M. Pantića za fototipsko izdanje jedinog poznatog primerka knjige sa inkriminisanim predgovorom u: P. JULINAC, Kratkoje vvedenije v istoriju proishoždenija slaveno-serbskago naroda, Beograd - Novi Sad 1981. $266-278$ 


\section{Četvrti primer}

Na model religijsko-političkog diskursa Orfelinovog Gorestnog plača... nadovezuje se pesma Jovana Rajića, takođe na ruskoslovenskom jeziku, Serbija ishodjašti v Kesariju... Nastala je u približno isto vreme, u ranim šezdesetim godinama već nalazimo njene prepise u rukopisnim pesmaricama. ${ }^{22}$ Objavljena je u Rajićevoj preradi Traedokomedije... Emanuila Kozačinskog krajem XVIII stoleća. Naslov pesme konotira na biblijsku temu izlaska jevrejskog naroda iz egipatskog carstva i njegov odlazak preko pustinje u obećanu zemlju. Eksplikativni prevod naslova glasio bi: „Srbija izlazeći (iz turskog carstva) u austrijsko (carstvo) peva ovu pesmu..... U samom tekstu nema nikakve potvrde da se s ovim naslovom mislilo na starozavetnu analogiju, sve do poslednje strofe u kojoj se uvodi religijski motiv. Pesma je do tada pesnička alegorija (alegorija in verbis). Sadrži dijalog sa „priskorbnom gorlicom" kojoj se postavljaju pitanja, na koja ona odgovara, redom, o tome zašto napušta svoj dom, kuda ide, i šta očekuje od onoga kod koga ide. Iz zavičaja odlazi jer je „hišni kobci i jastrebi“ povređuju i ruše gnezdo, a u austrijsko carstvo („Kesariju“) ide jer će tamo živeti mirno zaštitićena „orlom“ (heraldički znak austrijskog carstva). Na pitanje čime će ona uzvratiti „orlu“ za pruženu zaštitu i sigurnost, odgovara:

Orel krjepki na vsja strani,

Da slavitsja $v$ mirje i brani,

Sija jemu dari.

[Orao silni da se slavi u svim zemljama u miru i ratu, ovo su mu pokloni]

Na ponovljeno pitanje čime će još da slavi „orla“, sledi odgovor u završnoj strofi:

Verhu vodah da ljetjejet

I v pustinjah razbotjejet,

Sija ješce daju. ${ }^{23}$

\section{[ Iznad voda da leti i pustinje učini plodnim, Ovo još (ili: uz to) dajem ]}

Ova strofa unosi nov momenat u pesmu, i vraća nas asocijativnom polju naslova. Motiv sadržan u sintagmi „v pustinjah razbotjejet (goje se, tj. postaju plodna mesta u pustinji)“ je iz Biblije, u njenom ruskoslovenskom prevodu glasi „razbotejut krasnaja pustinji“ (Ps. Davidovi, gl. 64, 13). ${ }^{24}$ Javlja se u nizu psalama u kojima se slavi Bog čuvar, koji pruža utočište i spasenje. A tematski, kao što naslov upućuje, povezuje izlazak izraelskog naroda iz Egipta sa izlaskom Srba iz Turskog carstva. Orao se sada poistovećuje sa Gospodom. Tako pesma dobiva novi smisao, tačno bi bilo reći čita se na dva nivoa, doslovnom, kao alegorija in verbis, i prenesenom, duhovnom, kao alegorija in factis. Prvi smisao je više politički, govori o jednoj istorijskoj situaciji i odnosu prema njoj. Srbi su u austrijskom carstvu dobili zaštitu i sigurnost; izbegli su od nevolja i stradanja. Zbog toga će Srbija personificirana u „priskorbnoj gorlici“ biti odana Habzburškom dvoru, i uzvratiti mu vernošću. Ovaj stav, ako i nije Rajićev, dobra je ilustracija zvaničnog stava crkve. Pesma se, na tom, prvom ni-

22 Najstariji poznati tekst, bez poslednje strofe, nalazi se Pesmarici Teodora Dobraševića iz 1763. godine (v. Borivoje MARINKOVIĆ, Srpska građanska poezija, knj. II, Beograd 1966., 362). U vezi sa tim izražena je i sumnja u Rajićevo autorstvo. Mogućno da je ovu pesmu Rajić preuzeo i dodao joj poslednju strofu kojom joj je produbio smisao.

23 Jovan RAJIĆ, Tragedia sireč pečalnaja povest o smerti poslednago carja serbskogo Uroša pjatogo, Budim 1798., 62-63.

24 Vidi S. PETKOVIĆ, Rečnik crkvenoslovenskog jezika, Sremski Karlovci 1935. 
vou, može čitati i kao polemička u odnosu na druge pesničke tekstove, poput Orfelinova dva Plača, koji su ukazivali na loš položaj srpskog naroda u Habzburškoj monarhiji, i njegovo stradanje zbog nepoštovanja datih privilegija. Na drugom nivou pesma ima duhovni smisao: Gospod je bio zaštitnik jevrejskog naroda u njegovom istorijskom stradanju, tako će biti i Srbima. Ponovo se susrećemo sa tipološkim simbolizmom. Prvi nivo pesme jasan je i razumljiv, on alegorijom prenosi političku poruku; drugi nivo je skrovitiji, sadrži aluziju razumljivu teološki obrazovanom čitaocu. Njegov smisao je moralni, gotovo profetski. Savremenim istorijskim događajima dat je jedan providencijalni smisao. Rajićeva pesma je moderna, sekularizovana varijanta tipološkog simbolizma čije je poreklo u srednjovekovnoj patrističkoj egzegezi.

Orfelin i Rajić su se oslonili na tipološki simbolizam (figuraciju), u vrednovanju njima savremenih istorijskih događaja. Isti događaj povezali su sa različitim delovima Starog Zaveta, odnosno biblijske istorije jevrejskog naroda. Orfelin sa Vavilonskim tamnovanjem, Rajić (u poslednjoj strofi pesme) sa izlaskom iz Egipta. U prvom slučaju teritorija na kojoj se Srbi nalaze jeste mesto tamnovanja, u drugom - to je teritorija na koju su izašli iz tamnice. U oba slučaja događaji iz biblijske istorije su figura događaja u savremenoj istoriji. U jednome, ipak, postoji razlika. Orfelin je figuraciju upotrebio kao metod građenja pesme, u političke svrhe, da bi kritikovao (doslovno napao) crkvenu i habzburšku politiku. Kod Rajića, pak, postoji profetski elemenat, povezivanje duhovnog smisla sa budućnošću - ona je u okrilju crkve i vere u Gospoda. Tako se ove dve pesme sa naglašenim angažmanom za različite ideje, i različita gledanja na savremenost, na različite načine koriste tipološkim simbolizmom.

Iz opisane građe mogućno je isvesti zapažanja različita po vrsti, i nivou opštosti.

1. Svim ovim primerima zajednička je jasna veza sa ideologijama i politikom, ali sa druge strane iz opisa je razumljivo i da su to složene znakovne tvorevine koje se ne mogu svesti samo na jednu vrstu pojmova ili jednu funkciju. Kada Riter ispod grbova piše pesme u kojima objašnjava njihovu semantiku to nisu, nekakva „mistična“ tumačenja, ili pesničke igre koje služe zabavi, dakle nešto nebitno, pa prema tome nešto što ne treba da se razmatra, već postupak tumačenja grbova u ključu teorijskih shvatanja umetničkog stvaranja njegovog vremena. Na početku grbovnika nalaze se izdvojeni iz abecednog poretka grbovi Ilirika i Nemanjića, oni su izdvojeni jer su nosioci iste ideje koja karakteriše čitav prostor: nesklad (kontrast) između mogućnosti i sudbine. Jer, grb nije samo znak identiteta već je i nosilac određene ideje. Interpretativni okvir iz koga se iščitava ideja ima osnov u baroknoj poetici. Povezivanje udaljenih pojmova, oprečnih ili nespojivih, da bi se pomoću njih objasnila njegova suština, uobičajena je praksa toga vremena. I pogled na svet. Ovakvi oksimoronski spojevi, paradoksi, mogu se pronaći u bezbroj varijanti u svim umetnostima. Spaja se toplo sa hladnim, ljubav sa smrću, slava sa ništavnošću. Ovde je potpuno nebitno pitanje da li je ta Riterova ideja o Iliriku tačna, još manje da li je kao ideju povoljno ili nepovoljno vrednujemo, već da je to integralni deo grbovnika. On nije samo ono što nam izgleda da po svojoj nameni jeste, oznaka za teritorije, beleg državnosti odnosno identiteta, ideološki program, već su natpis i slika protumačeni u pesmi namenjeni čitaocu da mu saopšte ne- 
kakvu moralističku ideju, tako što će povezivanjem suprotnosti da ga začude i nateraju na razmišljanje. Krajnji ishod je didaktički. A da je u svesti autora to bio podjednako važan ili značajan aspekt pokazuje i njegova kompozicija: napred su izvučana dva grba koji sugerišu najopštiju ideju zajedničku ostalim grbovima. Kada se, opet, portret cara Dušana u srpskom izdanju Stematografije prikazuje dva puta, jedamput na početku grbovnika pobedonosno okruženog grbovima teritorija njegovog carstva i na kraju zbornika $s$ ukazivanjem na smrtni greh taštine i prolaznost slave, onda je tendencija ponovo moralistička, a način na koji je rečena treba čitaoca da začudi, i natera na razmišljanje. Pitanje onda glasi kako okarakterisati ovakve pojave, ako nam je cilj istorijska karakterizacija, kada su one kompleksne, višeznačne i spajaju u sebi raznovrsne tendencije, tj. pojmove koje mi danas vidimo kao odvojene, istoriju i moral, odnosno moral, politiku i lepo. Da li ćemo pojave posmatrati i prikazivati u njihovoj kompleksnosti, ili ćemo ih redukovati na jednan aspekt ili funkciju koja je zadata istraživačkim okvirom.

Kompleksnost bi mogla biti opšta karakteristika umetničkih pojava toga vremena. Hibridizacija žanrovskih karakteristika, mešanje različitih tradicija, kako na nivou stilsko-jezičkog izraza (mešanje srednjovekovnog sa novim, baroknim ili manirističkim tendencijama), tako i funkcija koje imaju u komunikaciji sa publikom (moralistička pouka, začuđavanje, ideološke ili upravo praktično-političke tendencije).

2. Drugo je pitanje odnosa tradicionalnog i novog, odnosno modernizacije. Možemo ga prevesti u pitanje o tipu ili tipovima promene. Da li se: (a) staro zamenjuje drugačijim (umesto jednog dolazi drugo); ili se (b) dodaje, odnosno na različite načine kombinuje; ili se: (c) novo adaptira na stare tradicionalne forme (prilagođavanje, „prevođenje“). Opisani primeri pokazuju različite tipove promene. Po svemu sudeći figuralizam poreklom iz zapadoevropskog hrišćanstva (katolicizam i razne varijante protestantizma) bio je ako ne ključni, onda svakako veoma prisutan oblik mišljenja. Mada sekularizovan i oslobođen providencijalnosti nije sasvim emancipovan od teološke podloge iz koje je izveden. Deo starog značenja (vertikalizam, direktno povezivanje udaljenih ,istorijskih“ pojava i apsolutnost njihovog značenja) sadržan je u novom, politički angažovanom figuralizmu. Ali, onda kada se javlja na različite načine se individualno artikuliše, pa se u upotrebi ovoga postupka mogu zapaziti razlike. Na slikama Joakima Markovića , u pesmama Zaharija Orfelina i Jovana Rajića svaki put je na drugačiji načine upotrebljen i individualno interpretiran. Dok je kod Rajića to jasno teološki osmišljeno, kod Orfelina su primetnije svetovne tendencije. Do sada nisu zapaženi primeri figuralizma pre XVIII stoleća, pa se može razumeti da je pojava, iznenađujuće proširena, očigledno nastala u kontaktu sa evropskom reformacijom, odnosno protureformacijom.

Upotreba stihova i strofičkih formi onda kada su one jasno metametrički označene kao nešto što je stranog porekla karakterišu dve vrste postupaka: modifikacije (prilagođavanja), i kopiranje (unošenje novog, netradicionalnog). Pavao Nenadović zamenio je u sapfičkoj strofi jedanaesterac tradicijskim trinaestercem koji se smatrao drevnim slovenskim stihom ekvivalentnim heksametru (njime je po pravilu i prevođen); Zaharija Orfelin je sestu rimu samo dopunio nerimovanim stihom, ako i takvu formu nije pronašao u nekom uzoru. To bi se moglo razumeti kao znak promenljivosti ili raznovrsnosti konteksta na koji se svako od njih oslanjao. U jednom slučaju se strano prilagođava domaćem, u drugom se novo (i strano) unosi sa neznatnom korekcijom ili bez nje. Mogu se opisati i kao dva različita stava. Po jednom strano se prilagođava i adaptira na domaću tradiciju, po drugom staro se zamenjuje novim. Odnos prema novom i drugačijem mogao bi se opisati kao više (ili manje) 
jedno nego drugo. Više, ili pre, unošenje novog, ili mešanje, kombinovanje tradicionalnog i novog (a i b), nego njegova adaptacija na domaću tradiciju (c).

3. Najzad, postoje razlozi i za određenu zapitanost nad pojmovnom aparaturom kojom se koristimo u opisivanju pojava koje proučavamo. Sintetički termini kao produženo trajanje srednjovekovlja, klasicizam ili barok, modernizacija, koje koristimo u poslovima karakterizacije umetnosti prve polovine XVIII stoleća nisu najpogodniji za njihov opis. Oni nam više prikrivaju, nego što objašnjavaju istorijske procese i njihove karakteristike; nezgrapni su, nedovoljno precizni. Problem je komlikovan pridavanjem vrednosnog značenja terminima modernizacija, barok, klasicizam, kao da je umetnost vrednija ili bolja samim tim što je barokna, ili da je ono moderno umetnički zrelije i uspelije od od onoga što je bilo pre. Niti barok, niti klasicizam nisu se razvili u prvoj polovini XVIII veka u toj meri da bismo mogli govoriti o konstituisanoj formaciji, već pre o komponentama, tendencijama, koje su u različitom stepenu razvijene, ili prisutne, u arhitekturi, slikarstvu, književnosti, ili tipu religioznosti. Njihovo prisustvo najčešće je povezano sa elementima tradicije, što je lako razumljivo iz opštih, društtvenih, i političkih okolnosti. Naporedo sa tendencijom da se prihvati novo, postojala je i težnja da se sačuva staro.

Zbog tesne povezanosti umetnosti sa društvenim razvojem trebali bismo potražiti drugačija rešenja. Naprosto, opis bi mogao za polazište uzeti ne stilske osobine, već ideologeme, kulturnu orijentaciju, ili politiku, a kao podređene elemente posmatrati njihove spojeve sa stilom. Periodizaciju bismo pravili prema etapama društvenog razvoja, a u okviru njih posmatrali razne tendencije i njihov stilski izraz. Ili bismo razlikovali nivoe, po opoziciji niža i viša, popularna i zvanična umetnost, i na taj način ih karakterisali. A ne samo pojmovima velike opštosti, i neodređenog značenja.

\section{$\cos$}

\section{Status der Kunst in Der ERsten Hälfte des i8. JH.S}

In dieser Arbeit wird erforscht, wie die Kunst in der ersten Hälfte des 18. Jh.s funktioniert. Dabei werden vier Beispiele aus der serbischen und kroatischen Kultur im Habsburgerreich von 1700 bis 1770 in verschiedenen Gattungen und Medien (Malerei und Literatur) analysiert. Anhand der Analyse der Beispiele kann man bestimmte Beobachtungen feststellen. Drei Veränderungsarten sind bemerkbar: (a) das Eigene wird durch das Neue und Fremde ersetzt; (b) das Traditionelle wird mit dem Neuen und Fremden kombiniert; (c) das Neue wird an die traditionellen Formen adaptiert. In den Beispielen sind eher Erscheinungen des Typs (a) und (b), als die des Typs (c) vertreten. Gattungshybridisierung und Komplexität außerästhetischer Funktionen charakterisieren die Kunst. Die synthetischen Begriffe, die für die Beschreibung der analysierten Beispiele verwendet werden, wie Barock, Klassizismus, verlängerte Dauer des Mittelalters, Modernisierung, bekommen zusätzliche wertende Bedeutungen. Sie sind zu verallgemeinernd und im Bezug auf auf den Stoff unzureichend geeignet. Es wird ein Zugang vorgeschlagen, in dem als Ausgangpunkte die Tendenzen in der Kultur, die Gliederung in niedere und höhere Kultur genommen werden und im Rahmen der kulturologischen Orientierungen die Stil- und Gattungserscheingungen beobachtet werden.

Stichwörter: serbische Kunst, kroatische Kunst, 18. Jh., Hybridysierung, Ästhetik. 


\section{$\cos$}

\section{Bibliografija}

Ivo BANAC, Grbovi, biljezi identiteta, Zagreb 1991.

Dmitri ČIŽEVSKI, „K problemam literatury barokko u slavjan”, Litteraria, XIII/1971.

Dinko DAVIDOV, Srpska Stematografija, Novi Sad 2011.

Arthur Charles FOX-DAVIES, The art of Heraldry, an encyclopedia of armory, London 1986 (1904).

Radoslav GRUJIĆ, Spomenica o srpskom pravoslavnom vladičanstvu pakračkom, Pakrac 1930.

Pavle JULINAC, Kratkoje vvedenije v istoriju proishoždenija slaveno-serbskago naroda, BeogradNovi Sad 1981.

Vjekoslav KLAIĆ, Život i djela Pavla Ritera Vitezovića, Zagreb 1914.

Mladen LESKOVAC, Antologija starijeg srpskog pesništva, Novi Sad - Beograd 1964.

Borivoje MARINKOVIĆ, Srpska građanska poezija, knj. II, Beograd 1966.

Dejan MEDAKOVIĆ, Putevi srpskog baroka, Novi Sad 1971.

Savo PETKOVIĆ, Rećnik crkvenoslovenskog jezika, Sremski Karlovci 1935.

Jovan RAJIĆ, Tragedia sireč pečalnaja povest o smerti poslednago carja serbskogo Uroša pjatogo, Bu$\operatorname{dim} 1798$.

Aleksandar SOLOVJEV, Istorija srpskog grba, Melbourne 1958.

Boris A. USPENSKIJ, Etjudy o russkoj istorii, Sankt-Peterburg 2002. 